\title{
Event review: Using multivariate analyses to interpret lithic variability: Contributions and limitations
}

\author{
Alice Leplongeon $^{1,2,3}$, Elena A.A. Garcea ${ }^{4}$ \\ 1. Department of Archaeology, KU Leuven. Celestijnenlaan 200e, bus 2409, 3001 Leuven, Belgium. \\ Email: alice.leplongeon@kuleuven.be \\ 2. Institute of Advanced Study and Department of Cultural Heritage, Alma Mater Studiorum University of \\ Bologna, Bologna, Italy \\ 3. UMR 7194 CNRS. Département Homme et Environnement, Muséum national deHistoire naturelle -Université \\ Perpignan Via Domitia, 1 rue René-Panhard, 75013 Paris, France \\ 4. Department of Letters and Philosophy, University of Cassino and Southern Latium, Via Zamosch 43, 03043 \\ Cassino, FR, Italy. Email: e.garcea@unicas.it
}

\section{Introduction}

A selection of papers presented at the Special Session 8 'Using multivariate analyses to interpret lithic variability: Contributions and limitations' held during the 2018 MetroArchaeo conference (22-24 October 2018, Cassino, Italy) is published in the Journal of Lithic Studies. Multivariate statistical analyses are increasingly used to discern patterns of variability in archaeological materials and help with their interpretation. Commonly used ones include Principal Component Analysis, Multiple Correspondence Analysis, Discriminant Analysis, Multiple Regression, General Linear Model, or Cluster Analysis, applied in various contexts of study: geometric morphometrics, spatial analysis or inter-assemblage comparisons.

The use of multivariate analyses in lithic material studies is not a new trend, but until recently it was mostly put into application by tenants of the 'Anglophone' school of lithic analysis in the frame of attribute analyses, whereas in its initial phase, tenants of the 'French' technological approach did (and to some extent sometimes still do) tend to reject any formal quantification (e.g., Pelegrin 2006; Perlès 2016; Soressi \& Geneste 2011; and for a review of the "French-Anglophone divide" see Hussain 2019: chapter 1). What perhaps is relatively new is that quantitative analyses are now increasingly used by proponents of a combined technological approach and attribute analysis (e.g., Hovers 2009; Nigst 2012; Scerri et al. 2014, 2016; Tostevin 2012), as well as by researchers who were initially trained in a qualitative technological approach (e.g., Hussain 2019: 265; Leplongeon 2017). This renewed - or at least more wide-spread - interest in quantitative analyses, somehow independent from the lithic analysts' research tradition, is particularly marked in studies dealing with data obtained through computer science approaches (such as 2D and 3D imagery techniques) (e.g., Grosman 2016; Shott \& Trail 2010). It also generated a renewed consideration of the issues related to why, when and how to apply multivariate statistics (see, for example, Grosman 2016; MacLeod 2018), in order to use them as a research means instead of an end, and not ISSN: 2055-0472. URL: http://journals.ed.ac.uk/lithicstudies/ 
falling in the pitfall described by Thomas in his 1978 paper on the 'awful truth about statistics": "Archaeologists seem, somehow, to have been led into the dead-end philosophy that complex statistical analysis will somehow make more sense of archaeological data" (Thomas 1978: 238).

However, this trend towards the use of quantitative methods, often motivated by the need for more replicability in lithic studies, does not entail homogenising lithic analyses. Choices made when applying these analyses to lithic data (in the type of analysis, sampling method, variables considered) depend on both characteristics of the lithic assemblages and, of course, research questions and goals. Their application is not always seen in the frame of the (classical) dichotomy qualitative vs quantitative approach, but on the contrary, their complementarity with other approaches is often underlined (e.g., Leplongeon 2017). In this aspect, it is interesting to note that the three papers presented in this volume are led by researchers initially trained in technological and mostly qualitative approaches to lithic artefacts.

This session aimed to bring together researchers who are using multivariate statistical analyses to study lithic assemblages. Through the presentation of case studies, methodological issues, referring specifically to the use of multivariate analyses and their relevance in a specific context (contributions vs. limitations), were discussed.

\section{The papers}

The first two papers of the session focus on the quantitative analysis of shape variability of bifacial tools in different contexts.

García-Medrano et al. (2020) investigate the morphological variability of a sample of handaxes from the Acheulean sites of Boxgrove and Swanscombe (UK) by comparing three ways of doing landmark-based geometric morphometrics (GM). These are (1) 2D GM analyses based on 28 semi-landmarks with a distribution concentrated on the tip and butt of the handaxes; (2) 2D GM analyses based on 60 semi-landmarks equally distributed; and (3) GM analyses of 3D models based on 5000 semi-landmarks. Results indicate that the more points are used to define a tool outline, the more accurate the interpretation of the variables of its shape is. Furthermore, the approach only focusing on the tip and the butt introduces a bias that does not allow to fully capture the differences in shape, whereas the two other approaches are more effective for interpreting shape variability according to the combination of planshape, profile-shape and tool topography. Both these approaches provide similar results in that they identify an opposition between the more oval handaxes from Boxgrove and the more pointed handaxes from Swanscombe, while 3D GM complement the previous analysis by including information on the shape of the profile.

Mesfin et al. (2020) explore variability in bifacial tools from three sites in the Congo Basin attributed to the Middle Stone Age Lupemban industry (M'Piaka, N'Zako Kono and N'Zako Ambilo) by using three complementary morphometric approaches. These are (1) analysis of five morphometric indices based on linear measurements; (2) the Log Shape Ratio method; and (3) GM using Elliptical Fourier Analysis of 2D outline based on 100 equidistant semi-landmarks placed from one main landmark positioned on the distal extremity. The centroid size of each outline was also computed. The first two approaches allow for the consideration of the general proportions of the bifacial tools, while the third one considers their shape in two dimensions. These data are then explored using principal component analysis and multivariate analysis of variance. Analyses were first conducted on all bifacial tools from the sites, and then on a specific type of bifacial tools, the Lupemban point. Results suggest a great intra-assemblage variability of bifacial pieces, while the main factor discriminating the provenance of the bifacial pieces is the centroid size. Regarding Lupemban 
points, all analyses show that Lupemban points from M'Piaka are morphologically different (smaller, thicker and less elongated pieces) from those from the other two sites. While these three approaches show similar results, they bring information on different aspects of the shape of the artefacts. This paper underlines the need to combine different morphometric approaches as well as to integrate results from other types of analyses, such as technological and functional analyses, in order to fully interpret morphometric variability of shaped tools.

The third paper by Fusco et al. (2021) examines lithic artefacts from both a qualitative technological and a quantitative perspectives. The authors combine a technological analysis with a quantitative approach using multivariate analyses to investigate the use of different raw materials, basalt and quartz, at the Middle Stone Age site of GOT 1-S (Gotera, southern Ethiopia). The paper aims at testing whether different exploitation and reduction strategies can be identified for these raw materials. The technological analysis of quartz artefacts denotes the use of Levallois and laminar methods, with careful core and platform preparation. Conversely, basalt cobbles are exploited using Levallois methods as well as a volumetric exploitation of their natural convexities following a more 'opportunistic' reduction strategy. These technological differences between quartz and basalt artefacts are confirmed by multivariate analyses (principal component analysis and cluster analysis), which show distinct characteristics (technological attributes, dimensions and shape) between the artefacts of these two raw materials. Further investigations during future fieldwork and analyses will clarify whether these different raw material exploitation strategies reflect a selection of the raw material according to the needs of the human group, or different occupations, and thus shifts in raw material management over time.

In these three papers, multivariate analyses are used to explore variability in lithic assemblages. While the authors identify a number of limitations and recommend their use in association with other types of analyses, they demonstrate that multivariate analyses can bring a significant contribution to comparative lithic studies.

\section{References}

Fusco, M., Carletti, E., Zerboni, A., Gallinaro, M. \& Spinapolice, E.E. 2021, Lithic variability and raw material exploitation at the Middle Stone Age (MSA) site of Gotera, southern Ethiopia: A combined technological and quantitative approach. Journal of Lithic Studies, 8(1): 29 p. doi:10.2218/jls.6530

García-Medrano, P., Maldonado-Garrido, E., Ashton, N. \& Ollé, A. 2020, Objectifying processes: The use of geometric morphometrics and multivariate analyses on Acheulean tools. Journal of Lithic Studies, 7(1): 16 p. doi:10.2218/jls.4327

Grosman, L. 2016, Reaching the Point of No Return: The Computational Revolution in Archaeology. Annual Review of Anthropology, 45(1): 129-145. doi:10.1146/annurevanthro-102215-095946

Hovers, E. 2009, The lithic assemblages of Qafzeh Cave. Oxford University Press, 320 p.

Hussain, S.T. 2019, The French-Anglophone divide in lithic research: A plea for pluralism in Palaeolithic Archaeology. PhD Thesis at University of Leiden, Leiden, The Netherlands, $470 \mathrm{p}$.

Leplongeon, A. 2017, Current approaches and new directions in lithic analysis: Defining, identifying and interpreting variability. Evolutionary Anthropology: Issues, News, and Reviews, 26(4): 145-148. doi:10.1002/evan.21530 
MacLeod, N. 2018, The quantitative assessment of archaeological artifact groups: Beyond geometric morphometrics. Quaternary Science Reviews, 201: 319-348. doi:10.1016/j.quascirev.2018.08.024

Mesfin, I., Leplongeon, A., Pleurdeau, D. \& Borel, A. 2020, Using morphometrics to reappraise old collections: The study case of the Congo Basin Middle Stone Age bifacial industry. Journal of Lithic Studies, 7(1): 38 p. doi:10.2218/jls.4329

Nigst, P.R. 2012, The Early Upper Palaeolithic of the Middle Danube Region. Leiden University Press, Leiden, 379 p.

Pelegrin, J. 2006, Long blade technology in the Old World: an experimental approach and some archaeological results. In: Skilled Production and Social Reproduction. Aspects of Traditional Stone-Tool Technologies, (Apel, J. \& Knutsson, K., Eds.), Stone Studies Vol. 2, Societas Archaeologica Upsaliensis, Uppsala: p. 37-68.

Perlès, C. 2016, La technologie lithique, de part et d'autre de l'Atlantique. Bulletin de la Société préhistorique française, 113(2): 221-240.

Scerri, E.M.L., Gravina, B., Blinkhorn, J. \& Delagnes, A. 2016, Can Lithic Attribute Analyses Identify Discrete Reduction Trajectories? A Quantitative Study Using Refitted Lithic Sets. Journal of Archaeological Method and Theory, 23(2): 669-691. doi:10.1007/s10816-015-9255-X

Scerri, E.M.L., Groucutt, H.S., Jennings, R.P. \& Petraglia, M.D. 2014, Unexpected technological heterogeneity in northern Arabia indicates complex Late Pleistocene demography at the gateway to Asia. Journal of Human Evolution, 75: 125-142. doi:10.1016/j.jhevol.2014.07.002

Shott, M.J. \& Trail, B.W. 2010, Exploring New Approaches to Lithic Analysis: Laser Scanning and Geometric Morphometrics. Lithic Technology, 35(2): 195-220. doi:10.1080/01977261.2010.11721090

Soressi, M. \& Geneste, J.M. 2011, Special Issue: Reduction Sequence, Chaîne Opératoire, and Other Methods: The Epistemologies of Different Approaches to Lithic Analysis. The History and Efficacy of the Chaîne Opératoire Approach to Lithic Analysis: Studying Techniques to Reveal Past Societies in an Evolutionary Perspective. PaleoAnthropology 334-350.

Thomas, D.H. 1978, The Awful Truth about Statistics in Archaeology. American Antiquity, 43(2): 231-244. doi:10.2307/279247

Tostevin, G.B. 2012, Seeing Lithics: A Middle-Range Theory for Testing for Cultural Transmission in the Pleistocene. American School of Prehistoric Research monograph series Oxbow Books, Oxford, 608 p. 